\title{
O Design Thinking Como Processo Estratégico, Tático e Operacional em Negócios Sociais
}

\author{
Design Thinking as a Strategic, Tactical, and Operational Process in Social Business
}

FERRO, Salles, Gláucia; Mestre; UFPR

glaucia@frontesul.com.br

HEEMANN, Adriano; Doutor; UFPR

adriano.heemann@gmail.com

\section{Resumo}

O presente artigo apresenta uma reflexão sobre negócios sociais, sua importância no âmbito contemporâneo, as diversas formas de seu entendimento e a possibilidade do Design Thinking servir como processo estratégico, tático e operacional deste tipo de empresa. Para tanto, foi desenvolvida uma revisão bibliográfica sobre os temas concernentes a esta investigação e uma entrevista com uma gestora de um negócio social. Tais averiguações permitiram aos autores apresentar sugestões de utilização do processo de Design Thinking em um negócio social visando o alcance não só de resultados eficazes, mas também do estímulo à inovação na gestão da empresa e no desenvolvimento de produtos e serviços.

Palavras Chave: Negócio Social; Design Thinking; Processo

\section{Abstract}

This article presents a reflection on social business, its importance in the contemporary context, the different forms of your understanding and the possibility of Design Thinking serve as strategic, tactical and operational process of this type of company. For that, a bibliographical review was developed on the topics concerning this investigation and an interview with a manager of a social business. These inquiries allowed the authors to present suggestions on the use of the Design Thinking process in a social business aiming not only at effective results but also at stimulating innovation in company management and in the development of products and services.

Keywords: Social Business; Design Thinking; Process 


\section{Introdução}

O valor dos negócios sociais para a realidade global cujos desafios se mostram cada vez mais complexos, tornam este fenômeno foco de estudo de variados campos do conhecimento, entre eles o design. Esta percepção se dá graças aos aspectos da abrangência do design que categorizado em diferentes especialidades como produto, serviço, gráfico, moda, e gestão, pode contribuir para o desenvolvimento e expansão deste tipo de empresa.

Também é importante notar que os negócios sociais estão envolvidos no âmbito da inovação social, a qual se destaca na história com mais ênfase a partir da globalização. Partindo deste entendimento, reforça-se o fato de que o estado deixou de atuar com efetividade para resolver as demandas sociais e passou a contar com as iniciativas privadas e muitas vêzes voluntária para sanar as deficiências. A expressão "Negócio Social" denota diferentes modelos de negócios em todo o mundo. Tal percepção refere-se às próprias características sociais, políticas, jurídicas e econômicas dos países. Por outro lado, este tipo de negócio envolve o enfrentamento de desafios difíceis de serem superados e a necessidade de um planejamento.

Visando a caracterização de um negócio social e o seu entendimento de acordo com a realidade brasileira, apresenta-se o caso da Badu Design, uma empresa com sede em Curitiba - PR cujo foco é o estímulo ao empreendedorismo feminino.

A partir de tais premissas, este artigo propõe o uso do processo do Design Thinking como ferramenta para se estabelecer um planejamento estratégico, tático e operacional para os negócios sociais. Tal proposta está vinculada às similaridades existentes entre as inteirações humanas típicas do negócio social e, ao mesmo tempo, a ênfase à empatia, à criatividade, à colaboração e à diversidade de stakeholders desejáveis em um processo de Design Thinking. Acredita-se que a inovação num processo de planejamento estratégico, tático e operacional de um negócio social surgirá como resultado em termos de gestão, produtos, serviços e envolvimento com as comunidades sociais.

\section{Revisão Teórica}

Tendo em vista o objeto deste artigo, esta revisão teórica se inicia com o tema Negócios Sociais. Na sequência é apresentado o conceito de Design Thinking (DT).

\subsection{Negócios Sociais}

Este tema é relativamente novo embora o conteúdo que embasa o seu conceito encontra respaldo parcial na literatura nos campos da administração, da economia, da sociologia, da história e da antropologia. Todavia, a revisão teórica aqui apresentada não se fundamenta nessas literaturas, mas nos modelos de negócios sociais praticados deste o evento da globalização.

Quando se fala em negócio social a primeira referência que se apresenta é Muhammad Yunus, economista, ganhador do prêmio Nobel da Paz em 2006 e criador do Grameen Bank, um banco de microcrédito criado na Índia. Yunus (2010) alega que um negócio conceituado como social não envolve perdas, não paga dividendos e direciona seus esforços para a 
realização de um objetivo social. Além disso, a ideia de lucros pessoais está excluída do âmbito deste tipo de empresa. Yunus (2010) ainda enfatiza que o principal objetivo do negócio social é resolver, na dimensão que for possível, um problema social e, para tanto, deve-se desenvolver métodos de negócios aplicáveis no contexto que se apresenta. O modelo de negócios pode ainda envolver a venda de produtos e serviços e pode contar com investidores e proprietários.

Yunus (2010) classifica dois tipos de negócios sociais. Tal classificação é apresentada no quadro 1:

Quadro 1 - Classificação dos tipos de negócios sociais

\begin{tabular}{c|l} 
Classificação & \multicolumn{1}{c}{ Descrição } \\
\hline Tipo 1 & $\begin{array}{l}\text { Empresa com receitas e despesas equilibradas, sem perdas e sem } \\
\text { dividendos, que se dedica a resolver um problema social. Seus } \\
\text { proprietários são investidores que reinvestem seus lucros na } \\
\text { expansão e melhoria do negócio. }\end{array}$ \\
\hline Tipo 2 & $\begin{array}{l}\text { Empresa com fins lucrativos de propriedade de pessoas pobres, } \\
\text { seja diretamente ou por intermédio de um fundo destinado a uma } \\
\text { causa social predefinida. }\end{array}$
\end{tabular}

Fonte: Os autores baseado em Yunus (2010, p.19 e 20)

Sob o viés do entendimento dos negócios sociais na Europa, Travaglini, Bandini e Mancione (2009) organizam as informações em 3 categorias: o primeiro envolve as empresas de integração ao trabalho. A segunda parte do princípio de que toda a produção de produtos e serviços nestas empresas tem por objetivo a causa social ou são de interesse coletivo. A terceira categoria envolve a participação do governo local e dos cidadãos visando a promoção do desenvolvimento social e econômico daquela região.

Por outro lado, a Organization for Economic Co-operation and Development (OECD, 1999) conceitua os negócios sociais como : organizações que buscam, com a atitude empreendedora, metas sociais e econômicas capazes de trazer soluções inovadoras para problemas de exclusão social e desemprego. Já a Social Enterprise Coalition (SEC, 2003) entende que as empresas sociais são negócios comerciais com propósitos sociais e ambientais e estes propósitos são o cerne de tudo o que é produzido na empresa.

O Reino Unido por meio do Departamento de Comércio e da Indústria (DTI, 2012) conceitua negócios sociais como aqueles que têm os objetivos primordiais ligados ao âmbito social e nos quais a receita é reinvestida com foco prioritário na comunidade e nos propósitos do negócio ao invés da maximização dos lucros dos sócios e acionistas.

Outro aspecto que chama a atenção na proposição europeia de negócio social é o estilo de governança que se pauta por sua característica transparente e participativa evitando assim as possibilidades de desvios de seus objetivos primários ligados ao âmbito social (GALERA; BORZAGA, 2009).

Segundo as características do modelo europeu de negócio social, Travaglini et al.(2009) apresentam os seguintes quesitos:

- Orientação para as causas sociais ou ambientais explícitas e o lucro é reinvestido para atingir os objetivos sociais; 
- Orientação para o mercado por meio da comercialização de produtos e serviços;

- Conceito de Propriedade social - a estrutura de governança é feita por meio da participação do grupo de pessoas envolvidas no negócio.

Como é possível notar, o modelo de negócio social europeu pode ser sintetizado pela gestão colaborativa e transparente da comunidade ligada a ele, além da importante atribuição do direito de propriedade (GALERA; BORZAGA, 2009; TRAVAGLINI et al., 2009).

Nos Estados Unidos por outro lado, os negócios sociais ganham uma multiplicidade de nomes e formas, mas, o que mais se relaciona com o que se entende por negócio social na Europa, no Brasil e na concepção de Yunus, é denominado nos Estados Unidos de iniciativa social. Assim, uma iniciativa social pode ser compreendida como qualquer ação empreendedora com foco no mercado mas que também tenha uma atividade comercial que produza um impacto social (KERLIN, 2006).

Desta forma, as características de tais negócios envolvem parcerias comerciais, empresas que nascem sob uma legislação específica, empresas multinacionais que mantém um viés social, entre outras (KERLIN, 2006; COONEY et al., 2014).

Outra percepção de negócio social encontra-se nos países emergentes no qual se inclui o Brasil. Em tais países existe um termo denominado "negócios inclusivos" e que foi cunhado pela rede social formada por 9 escolas de administração de empresas da América Latina. Os negócios inclusivos são definidos como organizações ou empreendimentos que geram transformação social por meio de atividades de mercado (COMINI, 2016). Neste sentido, tais os negócios inclusivos são as ONGs, empresas sem fins lucrativos que atuam em atividades do setor público e produzem bens e serviços. Assim, por enquanto, os negócios sociais nos países emergentes parecem estar mais ligados a sua própria atividade, intenção e modelo de gestão do que a uma legislação específica (GUTIÉRREZ; EZEQUIEL, TRUJILLO, 2006). Por outro lado, o conceito dos negócios inclusivos dos países emergentes está mais próximo do conceito dos negócios sociais europeus do que das iniciativas sociais dos norte americanos. Nos países emergentes há a participação das pessoas em riscos social e de baixa renda na produção de bens e serviços e na tomada de decisão dos negócios (COMINI, 2016).

O Brasil que encontra-se no conjunto de países emergentes e que por isso demanda uma atenção especial ao aspecto social, tem uma certa diversidade no âmbito dos negócios sociais ou negócios inclusivos.

\subsection{Design Thinking}

O Campo de pesquisa do design extrapola as delimitações de projeto de design em qualquer categoria seja o design de produto, o design de moda, o design gráfico ou qualquer outra (BUCHANAN, 1992). Corroborando com este entendimento o International Council Societies of Industrial Design (ICSID), organização que reúne associações de designers do mundo todo define o design como:

Uma atividade criativa cujo objetivo é estabelecer as qualidades multifacetadas de objetos, processos, seus sistemas em ciclos de vida completos. Portanto, design é o fator central da humanização inovadora de tecnologias e o fator crucial de intercâmbio cultural e econômico (ICSID,2017). 
Diante de tal definição é possível inferir que o design deixa de se restringir ao âmbito do projeto e passa a contribuir também para a gestão de empresas e para a geração de soluções em serviços, o que era, até então, restrito a outras áreas (BONI et al., 2014). Neste sentido, surge o conceito de design de negócios que envolve a abordagem do design em contraposição à abordagem tradicional de gestão empresarial (LIEDTKA e OLGILVIE, 2014). Nesta abordagem de design Fraser (2012) propõe a prática da colaboração multidisciplinar. Esta prática tem por objetivo assegurar que as atividades de desenvolvimento de negócios estejam voltadas à compreensão das necessidades dos clientes, à criação de experiência valor para os clientes e a concepção de estratégias competitivas empresariais. Como é possível notar, a abordagem de design para a gestão empresarial enaltece o papel do cliente no processo sem deixar de propor as estratégias competitivas empresariais. A abrangência do papel do design possibilitou um movimento de investigação e pesquisa para se alcançar métodos, processos e ferramentas para que o design pudesse contribuir de modo mais efetivo para a gestão empresarial. Nesta conjuntura, um processo que se sobressaiu foi o do Design Thinking (DT). A origem do termo se deu com mais ênfase nos anos de 1990 a partir do artigo de Buchanan (1992) "Wicked Problems em DT". Tal artigo faz uma reflexão acerca da fundamentação teórica do DT. Embora os conceitos abordados no artigo não consistam por si só em alguma inovação, o conjunto teórico ali investigado vem ao encontro de demandas empresariais que, a partir de então, passaram a exigir diferenciação. Assim, diversos autores (Quadro 2) começaram a investigar o tema propondo modelos, processos e abordagens do DT com o objetivo primordial de promoção da inovação.

Quadro 2 - Descrições do DT

\begin{tabular}{c|l} 
Autores & \multicolumn{1}{c}{ Descrição } \\
\hline Martin (2009) & $\begin{array}{l}\text { O DT é uma atividade de inovação. Funil do conhecimento } \\
\text { Mistério (investigação), Heurística (seleção de ideias) e Algoritmo } \\
\text { (criação de padrões replicáveis) }\end{array}$ \\
\hline Brown (2010, p.80) & $\begin{array}{l}\text { É a capacidade do pensamento integrativo que envolve a inspiração, } \\
\text { a experimentação e a implementação }\end{array}$ \\
\hline $\begin{array}{c}\text { Ambrose e Harrys } \\
(2011)\end{array}$ & $\begin{array}{l}\text { Processo de design.Etapas: Definição, pesquisa, geração de ideias, } \\
\text { teste com protótipos, seleção, implementação e aprendizado. }\end{array}$ \\
\hline Lockwood (2011) & $\begin{array}{l}\text { Inovação centrada no usuário : observação,colaboração, } \\
\text { visualização, protótipo e a análise da concorrência, inovação. }\end{array}$ \\
\hline $\begin{array}{c}\text { Stickdorn (2012, p.36) } \\
\text { É uma atividade voltada aos serviços centrados no usuário, é } \\
\text { cocriativo, é sequencial, é evidente (tangível) e é holístico }\end{array}$ \\
\hline $\begin{array}{c}\text { Liedtka e Ogilvie } \\
\text { (2014) }\end{array}$ & $\begin{array}{l}\text { O DT pode promover a inovação e o crescimento orgânico } \\
\text { empresarial por meio de ferramentas e processos. }\end{array}$
\end{tabular}

Fonte: Os autores baseados em Martin (2009), Brown (2010), Ambrose e Harrys (2011), Lockwood (2011), Stickdorn (2012, p.36), Liedtka e Ogilvie (2014).

Embora até o momento já tenham sido criados inúmeros modelos de processos de DT, o mais utilizado por pesquisadores e empresas parece ser o modelo proposto por Brown (2010). Neste modelo são demonstradas as fases de desenvolvimento de atividades para a resolução de desafios e a consequente promoção da inovação. 


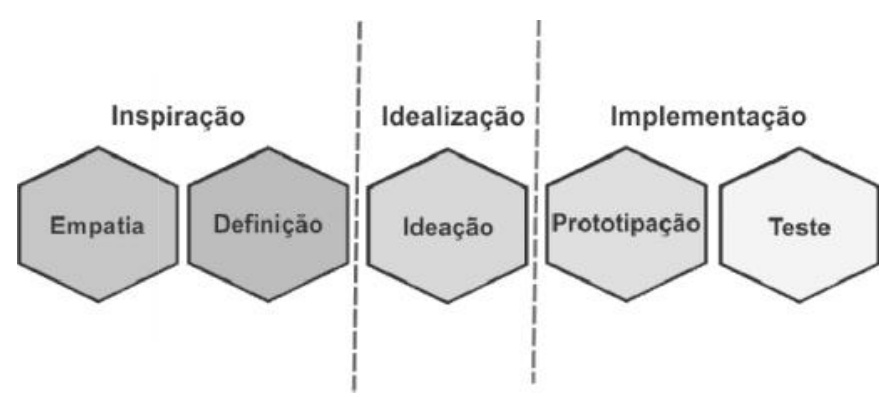

Fonte: Os autores baseados em Brown (2010)

As fases apresentadas no modelo de Brown (2010) são assim descritas:

- Fase da Inspiração - Constitui-se na fase de definição do problema ou oportunidade que motiva a busca por soluções;

- Fase da Idealização - Propõe o processo de gerar, desenvolver e testar ideias;

- Fase de Implementação - Diz respeito ao caminho que vai do local de criação ao mercado

As descrições de cada fase do processo de DT proposto por Brown (2010) representam atividades a serem desenvolvidas de modo colaborativo por equipes multidisciplinares. Estas fases embora sejam apresentadas de modo linear, podem ocorrer de modo iterativo.O autor defende ainda que quanto mais multidisciplinar for uma equipe de DT, melhores e mais inovadores serão os resultados alcançados. Por outro lado, para que as tarefas de cada fase sejam realizadas faz-se necessário o uso de ferramentas operacionais. Tais ferramentas são específicas para o alcance dos objetivos das etapas e não são obrigatoriamente ferramentas de design.Assim, algumas ferramentas da fase de inspiração são apresentadas no quadro 3.

Quadro 3 - Descrição de algumas ferramentas do DT utilizadas na Fase de Inspiração

\begin{tabular}{c|l} 
Ferramentas & \multicolumn{1}{|c}{ Descrição } \\
\hline Pesquisa Desk & É a busca de informações confiáveis de dados secundários \\
\hline Cartões de & $\begin{array}{l}\text { São reflexões pessoais embasadas em dados reais obtidos na pesquisa } \\
\text { exploratória. Posteriormente são utilizados para um brainstorming }\end{array}$ \\
Insights & $\begin{array}{l}\text { Agrupamento de cartões com inspirações dos participantes do workshop } \\
\text { colaborativo visando similaridades entre as ideias }\end{array}$ \\
\hline Afininidades & $\begin{array}{l}\text { É uma organização visual gráfica construída para organizar uma ideia, } \\
\text { proposta, dados de campo, entre outros }\end{array}$ \\
\hline Mapa &
\end{tabular}

Fonte: Os autores baseados em Viana et. al. (2011)

Algumas ferramentas da fase de Idealização (quadro 4) são propícias para induzir um grupo colaborativo a criar soluções a partir de um desafio proposto. Esta fase envolve uma liderança para que os limites de tempo e objetivos sejam alcançados. 
Quadro 4 - Descrição de algumas Ferramentas do DT utilizadas na Fase de Idealização

\begin{tabular}{c|c} 
Ferramentas & Descrição \\
\hline Brainstorming & $\begin{array}{l}\text { Estímulo dado e controlado por um moderador para a atividade em grupo } \\
\text { para a geração de um grande número de ideias de modo rápido }\end{array}$ \\
\hline $\begin{array}{c}\text { Workshop de } \\
\text { Cocriação }\end{array}$ & $\begin{array}{l}\text { Encontro organizado na forma de uma série de atividades em grupo com o } \\
\text { objetivo de se alcançar algum objetivo de modo criativo e colaborativo }\end{array}$ \\
\hline $\begin{array}{c}\text { Cardápio de } \\
\text { Ideias }\end{array}$ & Catálogo apresentando a síntese de todas as ideias geradas no projeto \\
\hline $\begin{array}{c}\text { Matriz de } \\
\text { Posicionamento }\end{array}$ & Analise estratégica das ideias geradas.Utilizada com outras ferramentas
\end{tabular}

Fonte: Os autores baseados em Viana et. al. (2011)

A partir do levantamento de ideias geradas por meio das ferramentas da fase de idealização, os participantes de um projeto de DT procurarão escolher as melhores ideias e prototipá-las visando sua validação. Embora seja apresentada na fase final do processo (quadro 5), a prototipação pode ocorrer em qualquer momento (VIANA et al., 2011).

Quadro 5 - Descrição de algumas ferramentas do DT utilizadas na Fase de Implementação

\begin{tabular}{|c|c|}
\hline Ferramentas & Descrição \\
\hline $\begin{array}{l}\text { Protótipo em } \\
\text { Papel }\end{array}$ & $\begin{array}{l}\text { Representações de interfaces gráficas com diferentes níveis de fidelidade. } \\
\text { Pode ganhar complexidade a partir de testes com usuários }\end{array}$ \\
\hline $\begin{array}{l}\text { Modelo de } \\
\text { Volume }\end{array}$ & Representações de um produto não funcional.Vários níveis de fidelidade \\
\hline Encenação & $\begin{array}{l}\text { Simulação improvisada de uma situação com pessoas para encenar } \\
\text { aspectos de um serviço }\end{array}$ \\
\hline Storyboard & $\begin{array}{l}\text { Representação visual de uma história por meio de quadros estáticos } \\
\text { compostos por desenhos, colagens, fotos ou outra técnica disponível }\end{array}$ \\
\hline
\end{tabular}

Fonte: Os autores baseados em Viana et. al. (2011)

Sinteticamente é possível inferir que as características que delineiam o processo do DT segundo Brown (2010) são : a colaboração, a empatia, as equipes multidisciplinares, a iteratividade e a criatividade, tudo ocorrendo por meio do método abdutivo que formula hipóteses explicativas.

Tendo em vista a apresentação do conceito, do processo, e das ferramentas do DT é importante destacar as aplicações deste tema no âmbito da gestão empresarial. Assim, Schlemm (2008) formulando um pensamento numa entrevista com Buchanan reforça este entendimento.

\footnotetext{
Quando introduzimos o conceito de DT no âmbito da gestão estratégica, a primeira reação das pessoas é buscar sua referência no conceito histórico do design, comumente associado à forma das coisas. Como novo campo de estudo, entendemos que não lidamos com uma simples questão semântica; há algo a ser superado para que este novo entendimento seja assimilado na comunidade acadêmica e no mundo corporativo. (SCHLEMM, 2008, p.269).
}

Buchanan em resposta à reflexão de Schlemm (2010), entende que essa superação se dá 6o GAMPI Plural, 2017, Joinville, SC. 
nos níveis 3 e 4 do design, onde o interesse deve estar voltado às ações, aos processos, às interações aos ambientes e aos sistemas nos quais as interações ocorrem. Corroborando com este entendimento, Mozota et al. (2010) delineiam o papel do design no âmbito estratégico, equivalente ao quarto nível proposto por Buchanan. Os autores afirmam que a gestão do design é um fator preponderante que pode ocorrer por meio da criação de uma política de design, da gestão dos recursos do design e da construção de uma rede de informações e ideias. Mootee (2013) indicando como a gestão do design pode ocorrer na prática, afirma que o DT pode ajudar nas interações humanas organizadas em times para cultivar a inclusão, a criatividade e a empatia visando o alinhamento das percepções desses participantes em torno de objetivos comuns.

Por outro lado, o terceiro nível da gestão do design pode ser entendido com o nível tático no qual, de acordo com Best (2006), o time, o processo e os sistemas de uma empresa utilizam o design para auxiliar a atingir as metas organizacionais. Neste mesmo sentido, é possível inferir que os líderes de nível médio como gerentes, designers sênior e gerentes de projetos de uma organização possam caracterizar os responsáveis por liderar o processo do DT no nível intermediário, articulando ideias e formando times colaborativos e multidisciplinares para o alcance das metas.

Já segundo Buchanan (1992), os 2 primeiros níveis do design seriam atribuídos à fase operacional e suas particularidades técnicas, logísticas, de organização e de construção. Neste sentido, Löbach (2000) mais tarde enfatiza o papel criativo do designer na fase operacional afirmando que o designer por meio de seu repertório pessoal e profissional deverá ser capaz de associar determinadas informações com um problema, estabelecendo novas relações entre elas. Daí a criação de produtos e serviços inovadores que propiciarão à empresa a diferenciação no mercado.

Segundo Best (2006) o nível operacional no qual o design se manifesta envolve a materialização dos produtos e serviços e a entrega ao usuário. Tal entrega caracterizada como final seria responsável pelo contínuo feedback previsto no processo de DT.

Buscando construir uma síntese da percepção do papel do DT nos aspectos Estratégico, Tático e Operacional da gestão empresarial é importante ressaltar que a adoção do processo do DT neste contexto tem por objetivo primordial a eficácia da gestão e a promoção da inovação nos diferentes níveis. Mais recentemente, Mootee (2013) assevera que esta gestão da inovação por meio do DT é mais do que apenas planejar novos produtos e serviços, é imaginar, organizar, mobilizar e competir de forma diferente. Para fazer isso com algum grau de sucesso, as organizações devem quebrar padrões para que surjam novas ideias.

\section{Método}

Inicialmente foi realizada uma revisão teórica envolvendo em primeiro lugar a compreensão do cenário global que abrange os diferentes conceitos de negócio social. Uma vez compreendida a diversidade conceitual do tema, foi possível estabelecer strings de busca inseridos no portal de periódicos da Capes (2017) para encontrar artigos científicos e informações relevantes sobre os títulos: Social Business, Social Initiative, Negócios Inclusivos, Inclusive Business, Muhammad Yunus.

Para o tema "DT" o processo de busca de informações ocorreu por meio da percepção de que entre milhares de artigos que investigam o assunto, alguns autores são mais recorrentes e entre eles está Buchanan (1992) que busca fundamentar o termo. Na sequência, os autores 
mais recorrentes e que propõem um processo de DT são, Martin (2009) e Brown (2010). Finalmente foi possível criar strings de busca para pesquisa de assunto no portal de periódicos da Capes (2017) dos temas: Strategic Design, Design Estratégico, Design Management, Gestão do Design, DT e Strategy. Os conceitos investigados foram apresentados no contexto de um negócio social denominado Badu Design. As informações coletadas deste negócio social ocorreu por meio de uma entrevista com a gestora.

\section{Discussão}

O DT entre tantas especialidades do design, é o que se apresenta como uma prática profissional colaborativa, multidisciplinar, criativa, com foco em gestão e centrada no ser humano. Visando a compreensão da associação do DT ao negócio social apresenta-se o caso da Badu Design, uma empresa com sede em Curitiba. Este negócio engloba vários projetos (nome dado às diferentes iniciativas sociais), mas o que está sendo enfocado neste artigo tem por objetivo o empreendedorismo feminino por meio do incentivo à atividade profissional. Essa atividade profissional não requer um ambiente de trabalho específico. As mulheres recebem capacitação para abrirem microempresas e produzirem produtos de cartonagem e costura. Parte da matéria prima utilizada na fabricação dos produtos são refugos de tecido doados pelas indústrias têxteis locais. Os produtos finais são comercializados gerando renda para essas mulheres.

Figura 2 - Empreendedoras e produção
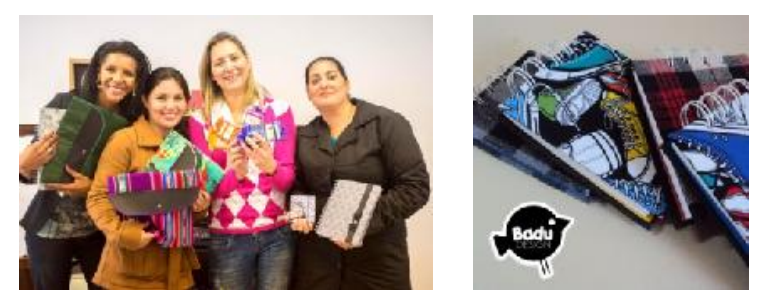

Fonte : Arquivo Badu Design

A gestão atual deste negócio social ocorre prioritariamente por meio da gestora que conta com parcerias de profissionais voluntárias e eventualmente, por programas da iniciativa privada de fomento ao empreendedorismo social. Assim, como se pode notar, um negócio social já nasce baseado na empatia que é um dos princípios de DT.

Por outro lado, para a perpetuação da Badu Design e da ampliação de seus projetos sociais, é indispensável o delineamento da visão de longo prazo. Neste sentido, surge a necessidade da elaboração de planos nos âmbitos estratégico, tático e operacional que pode ocorrer por um processo de DT.

O plano estratégico da Badu Design pode ser delineado com a equivalência da percepção da fase 1 do processo de DT denominada de "Inspiração". Nesta fase se constroem redes de informações e ideias com visão de futuro baseadas na percepções atuais de seus gestores e stakeholders convidados (como consultores e mentores). Assim, por meio da "pesquisa desk" é possível se mapear as tendências econômicas, sociais, de design e de todas as áreas. Além disso, é possível identificar o que ocorre no cenário atual externo que pode impactar a Badu Design. A partir de tais delineamentos, a ferramenta "cartões de insight" 
possibilitará aos gestores e convidados a documentação das visões individuais. Estas visões, serão compartilhadas e analisadas em um "diagrama de afinidades" e finalmente detalhadas em um "mapa conceitual". Este mapa torna-se uma referência visual do plano estratégico.

Figura 3 - Mapa Conceitual - 1o esboço

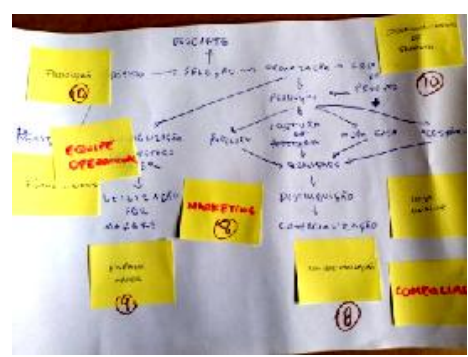

Fonte: Os autores

No âmbito tático, a associação com o processo de DT se dá em equivalência com a fase de "Idealização", onde líderes inicialmente voluntários da Badu Design, podem articular ideias em "workshops de cocriação" e usar os "cardápios de ideias" para sugerir novas linhas de produtos, treinamentos, logística, distribuição e vendas. E, a partir daí, aprofundar tais entendimentos propondo uma "matriz de posicionamento". Esta matriz possibilitará a votação das ideias mais viáveis para serem prototipadas.

Figura 4 - Workshop de Cocriação na Badu Design

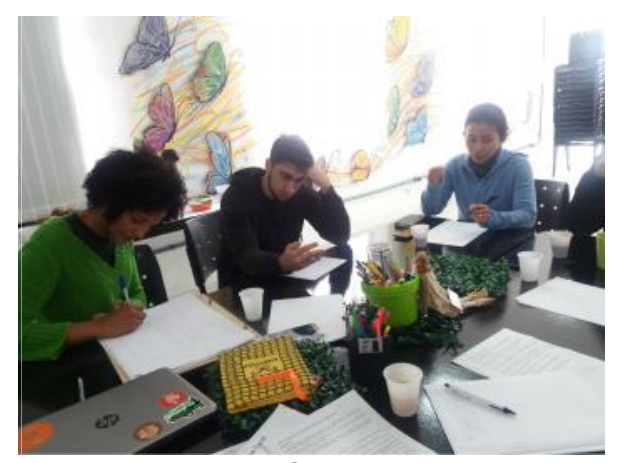

Fonte: Os autores

As sugestões advindas da etapa de idealização geram os protótipos de produtos e testes de serviços que se estabelecem em concordância com a fase de "Implementação" do DT. Nesta fase a experiência do designer e sua capacidade de associação de informações proverá ao time operacional elementos para a melhor execução das tarefas. Os protótipos de produtos podem ser feitos em baixa resolução e os serviços podem ser encenados. Os resultados preliminares de tais testes servirão para a mitigação de possíveis prejuízos de tempo e financeiros. Além disso, poderão ser testados quanto ao seu grau de inovação.

Como a Badu Design trabalha com refugos de tecidos para alguns produtos, tais testes podem ser feitos com a mesma matéria prima que será usada no produto final. Já o teste dos serviços podem ser realizados com empreendedoras e produtoras mais experientes sob a supervisão da gestora que atualmente também atua na esfera operacional. 
Nesta sugestão de uso do DT como processo para planejamento estratégico, tático e operacional do negócio social, evidencia-se a equivalência de cada etapa do DT com cada tipo de plano. No entanto, é possível um experimento no qual o processo do DT seja aplicado integralmente aos planos estratégico, tático e operacional. Os resultados podem ser diferentes.

É importante ressaltar que o processo de DT tem uma característica iterativa, ou seja, independente da fase em que se encontre o planejamento, a qualquer momento as atividades que estão sendo desenvolvidas podem revisitar a fase anterior ou projetar uma ideia ou um protótipo para a fase posterior. Esta maleabilidade do processo cria uma dinâmica que estimula a colaboração, o aspecto lúdico e a inovação.

\section{Conclusão}

O artigo aqui apresentado propôs um mapeamento dos tipos de negócios sociais existentes no mundo, bem como suas diferentes nomenclaturas e modelos de atuação.

Foram apresentados diferentes teóricos que aprofundaram o entendimento sobre os negócios sociais no Brasil, nos Estados Unidos e na Europa.

$\mathrm{Na}$ continuidade, o artigo apresentou o conceito de DT sob o entendimento dos autores mais recorrentes sobre o tema encontrados em pesquisas a nível mundial. Foram evidenciados os conceitos basilares do DT como: empatia, iteratividade, colaboração multidisciplinar e criatividade. Tais conceitos corroboraram para que fosse sugerida a aplicação do DT como processo no âmbito do planejamento estratégico, tático e operacional de um negócio social. Esta proposição se embasa no fato do negócio social ter características em comum com o DT.

Tendo em vista o aspecto prático desta proposta foi apresentado um negócio social denominado Badu Design no qual se pode aplicar o processo do DT .

Este artigo não pretende sugerir que o DT sirva como um processo a ser aplicado com exclusividade no âmbito dos negócios sociais, mas sim enfatizar a similaridade de conceitos e premissas que regem a prática do DT e dos negócios sociais. Estas similaridades permitem uma agilidade na compreensão do processo, uma facilidade para a execução das tarefas, um rápido engajamento das equipes colaborativas multidisciplinares e a possibilidade do alcance de resultados mais inovadores.

\section{Agradecimento}

Os autores agradecem ao CNPQ pelo apoio à pesquisa na forma de bolsa de estudos

\section{Referências Bibliográficas}

AMBRoSE.G,HARRYS.P. DT: Ação ou Prática de Pensar o Design. Bookman. Porto Alegre. RS: 2011

BEST, K. Design Management: Managing Design Strategy, Process and Implementation. Switzerland, AVA : 2006

BADU DESIGN - www.badudesign.com.br - Pesquisa realizada em Agosto de 2017

BONI.R. C.; SILVA.K.; SILVA.P. C. J. - Os limites do Design e a Relação com a Arte e a Indústria. Em anais do $11^{\circ} \mathrm{P} \&$ D Design. Gramado - RS. 2014 
BROWN.T. DT: uma metodologia poderosa para decretar o fim das velhas ideias. Campus Elsevier.RJ.2010

CAPES - Coordenação de Aperfeiçoamento de Pessoal de Nível Superior - Fundação vinculada ao ministério de Educação do Brasil. www.capes.gov.br . Pesquisa realizada em 25 de Maio de 2017

COMINI.M. G. - Negócios Sociais e Inovação Social; Um retrato de Experiências Brasileiras. Tese Departamento de Administração FEA USP. SP: 2016

COONEY.K.; KOUSHYAR.J.; LEE.M.; MURRAY.J. - Benefit Corporation and L3C Adoption: a Survey. Stanford Social Innovation Review, v. online. EUA: 2014.

DTI - Social Enterprise: a Strategy for Success. 2012. <http://www.dti.gov.uk/>. Pesquisa realizada em 03/06/2017

FRASER.H.- Design para Negócios na Prática - Elsevier. RJ. 2013

GALERA.G.; BORZAGA. C. - Social Enterprise - An International Overwiew of its Conceptual Evolution and Legal Implementation. Social Enterprise Journal, v.5, n.3,p. 2010-228. UK: 2009

GUTIÉRREZ.R.; EZEQUIEL.R.; TRUJILLO.D. - Empresas Sociales: Una Especie en Busca de Reconocimiento? Revista de Administração - RAUSP. V.41, N4, P.341-351, SP: 2006

ICSID - International Council Societies of Industrial Design - Design Definition http://wdo.org/. pesquisa realizada em 20/05/2017

KERLIN.J. - Social Enterprise in the United States and Europe: Understanding and learning from the differences. International Journal of Voluntary and Nonprofit Organizations. Springer v, 17, $\mathrm{n}^{\circ} 3$, p. 251. EUA: 2006

LIEDTKA.J; OGILVIE. T. DT. Um kit de Ferramentas para o crescimento rápido da sua empresa. HSM. SP: 2014

LÖBACH, B. - Diseño industrial. G.G., Barcelona :2000.

MARTIN, Roger. Design de Negócios. Campus, São Paulo: 2010

MOOTEE.I. - DT for Strategic Innovation - What they can't teach you at business or design school. Wiley, USA: 2013

MOZOTA, B. B.; KLÖPSCH, C.; COSTA, F. C. X. - Gestão do Design. Rio Grande do Sul: Bookman: 2010.

OECD - Organization for Economic Co-operation and Development - Better Policies For Better Lives. http://www.oecd.org/. Paris. Pesquisa realizada em 04/06/2017.

SCHLEMM.M. M. - Como o DT Contribui para a Gestão Estratégica. Revista Brasileira de Estratégia. Curitiba. PR. v. 1. n 3 P. 267-273: 2008.

SEC - There is more to Business Than you Think. A guide to Social Enterprise. London Social Enterprise Coalition. London: 2003

STICKDORN.M.; SCHNEIDER. J. - This is Service DT. John Wiley Professional. USA: 2012.

TRAVAGLINI.C.; BANDINI.F.; MANCIONE.K. - Social Enterprises in Europe; Governance models. An analysis of Social Enterprises Governance Models Though a Comparative Study of The Legislation of Eleven Countries. In: 2nd EMES International Conference on Social Enterprise. Trento - Italy: 2009.

YUNUS, Muhammad. Criando um Negócio Social - Como Iniciativas Economicamente viáveis podem solucionar os grandes problemas da sociedade. Editora Campus/Elsevier. Rio de Janeiro: 2010 